\title{
Ammonium phosphate in sori of Dictyostelium discoideum promotes spore dormancy through stimulation of the osmosensor ACG
}

\author{
David A. Cotter, ${ }^{1}$ Andrew J. Dunbar, ${ }^{2}$ Stanley D. Buconjic ${ }^{1}$ \\ and John F. Wheldrake ${ }^{2}$ \\ Author for correspondence: David A. Cotter. Tel: + 15192534232 ext 5042. Fax : + 15199713609. \\ e-mail: cotter1@server.uwindsor.ca
}

1 Department of Biological Sciences, University of Windsor, 401 Sunset Avenue, Windsor, Ontario, Canada N9B 3P4

2 School of Biological Sciences, The Flinders University of South Australia, Bedford Park, GPO Box 2100, Adelaide 5001, Australia
The sori of Dictyostelium discoideum (strains SG1, SG2, NC4 and V12) contained more than $100 \mathrm{mM}$ ammonium phosphate. Glutamine synthetase (GS), which could remove ammonia from the sorus, was not present in 2-d-old dormant spores but enzyme activity returned to vegetative levels after spore germination. Based on mRNA blotting, the activity of this enzyme in germinating spores appeared to be transcriptionally controlled. At the same time that GS activity was increasing, ammonia was released from germinating spores. Exogenous ammonium ions at a concentration of $28 \mathrm{mM}$ did not block germination nor modulate GS activity in nascent amoebae. It was concluded that the transcription and translation of GS is not environmentally regulated but is an integral part of the germination process, preparing nascent amoebae for vegetative growth. An exogenous concentration of $69 \mathrm{mM}$ ammonium phosphate could maintain dormancy in spores of strains SG1 and SG2 for at least a week in the absence of any other inhibitory component from the sori. The inhibition was reversible at any time either by dilution or by washing the spores free of the ammonium ion. Spores of strain acg were not inhibited by $100 \mathrm{mM}$ ammonium phosphate. A model is presented in which GS in prespore cells serves as a sink for ammonia to allow the osmotically sensitive adenylyl cyclase aggregation protein (ACA) to activate protein kinase A (PKA) to induce fruiting-body formation. After fruiting-body formation is complete, the decline in GS and ACA activities in developing spores is offset by their replacement with the osmotically and ammonia-stimulated adenylyl cyclase osmosensor for germination (ACG). Ammonia and discadenine may act as separate signals to synergistically activate PKA by stimulating ACG activity while inhibiting CAMP phosphodiestrase activity in fully dormant spores.

Keywords: Dictyostelium discoideum, glutamine synthetase, spore dormancy, ammonia inhibition, adenylyl cyclases

\section{INTRODUCTION}

Ammonia is produced throughout multicellular development by protein degradation using powerful lysosomal enzymes (North \& Cotter, 1991; Bonner, 1993; North et al., 1996), various transaminases (Krivanek \& Krivanek, 1965), and glutamate dehydrogenases (Wright

Abbreviations: ACA, adenylyl cyclase for cellular aggregation; ACG, adenylyl cyclase osmosensor for regulation of spore germination; GDH, glutamate dehydrogenase; GS, glutamine synthetase; MSX, L-methionine sulphoximine; PKA, protein kinase $A_{\text {: }}$
\& Bard, 1963; Pamula \& Wheldrake, 1990, 1991, 1992, 1996). About half of all the protein accumulated by vegetative cells of Dictyostelium discoideum is consumed in construction of the final fruiting body (see Loomis, 1975). The use of protein as a metabolic fuel for development releases large quantities of ammonia, which can regulate cell determination; thus $33 \mathrm{mM}$ $\left(\mathrm{NH}_{4}\right)_{2} \mathrm{SO}_{4}$, inhibits transcription of prestalk genes but stimulates transcription of prespore genes (Oyama \& Blumberg, 1986), and concentrations of ammonia from 50 to $100 \mathrm{mM}$ reversibly block aggregation, tip formation and culmination (Davies et al., 1996). Evidence 
that prestalk cells produce most of the ammonia postaggregation, while prespore cells become rich in specific amino acids such as glutamine, glutamate and asparagine, has led to a hypothesis called the ammonia source and sink model (Cotter et al., 1992). In this, a portion of the ammonia produced by prestalk cells (source) is consumed by prespore cells (sink) in the production of specific amino acids (Cotter et al., 1992). The TCA cycle of mitochondria should have different functions in the two cell types: in the prestalk cells, to consume glutamate and aspartate producing carbon dioxide and ammonia; in prespore cells to produce glutamate and aspartate using precursors derived from glycogen. Glutamine production would require that glutamine synthetase (GS) be active in consuming glutamate and additional ammonia in prespore cells, and indeed, it is present in vegetative cells. Its specific activity increases during differentiation and it is highly localized in prespore cells (Dunbar \& Wheldrake, 1995, 1997a). Its activity is maximal at culmination, and declines during formation of the fruiting body (Dunbar \& Wheldrake, 1995, 1997a).

The fruiting body consists of an upright column of dead stalk cells supporting a viscous droplet of dormant spores known as the sorus (Raper, 1984). For about four days after spore formation, the 'young' spores do not germinate when washed and placed in phosphatebuffered solutions (Cotter \& Glaves, 1989). They will germinate synchronously, however, if they are heat shocked at $45^{\circ} \mathrm{C}$ for $30 \mathrm{~min}$ after being washed free of autoinhibitors such as discadenine, a zeatin-like molecule (Abe et al., 1976; Cotter \& Glaves, 1989). Young spores also respond and germinate when bacterial growth products called 'promoters' overcome the inhibition imposed by discadenine (Ihara et al., 1990). When fruiting bodies are aged for $10-14 \mathrm{~d}$ at room temperature, the 'mature' spores gain the ability to germinate spontaneously (autoactivate) if washed and placed in phosphate-buffered solutions. During the initiation of spore swelling, autoactivating spores release an 'autoactivator' which may overcome discadenine and greatly increase the rate as well as the synchrony of spontaneous germination in the rest of the spore population (Cotter \& Glaves, 1989). Mutant spores called 'premature-maturation mutants' or 'spontaneous germinators' have been isolated and named SG1 and SG2. These mutants gain the ability to autoactivate after only $1 \mathrm{~d}$ of ageing. They release autoactivator(s) with the same chromatographic characteristics as aged wildtype spores (Dahlberg \& Cotter, 1978).

The interactions of autoactivators and autoinhibitors, as well as osmotic-pressure effects, suggested that dormancy and spore germination in D. discoideum were regulated by classical signal-transduction pathways (Cotter \& Glaves, 1989; Glaves \& Cotter, 1989; Cotter et al., 1990). More recent work has indicated that spore dormancy in the fruiting body is maintained by at least two inhibitory cascades (Cotter et al., 1992). The first involves low-molecular-mass autoinhibitors that stimulate tyrosine phosphorylation of actin, preventing cyto- skeletal rearrangements and thus spore swelling (Gauthier et al., 1997; Kishi et al., 1998). This cascade may originate when discadenine activates the transmembrane two-component histidine kinase DHKB (Zinda \& Singleton, 1998). The active DHKB may in turn, through a series of phosphoryl relays, inactivate the phosphodiesterase activity of RegA, allowing cAMP to rise and contributing to the high protein kinase $\mathrm{A}$ (PKA) activity of dormant spores. The second inhibitory cascade is regulated by the osmotic pressure of the extracellular material of the sorus. It is commonly observed that the sorus volume varies directly with humidity. Thus, low relative humidity results in drying of the sorus and an increase in osmotic pressure upon the spores. The sporulation-specific adenylyl cyclase (ACG) is a membrane-bound osmosensor and directly produces cAMP in response to osmotic pressure (van Es et al., 1996; Virdy et al., 1999). The pressures required in vivo to activate ACG and so maintain spore dormancy in the sorus may be simulated in vitro with glucose or sucrose solutions ranging from 100 to $250 \mathrm{mM}$ (Cotter, 1977; van Es et al., 1996; Virdy et al., 1999). In osmotically inhibited spores, the increase in cAMP activates PKA to phosphorylate a number of 'dormancy proteins' (Lydan et al., 1994a ; van Es et al., 1996; Virdy et al., 1999). If the relative humidity is high, the sorus absorbs moisture from the air, and the lower osmotic pressure allows mature spores to produce autoactivators. The autoactivators override the autoinhibitors and activate a phospholipase $C$ pathway that mobilizes $\mathrm{Ca}^{2+}$, which then interacts with calmodulin and calmodulin-binding proteins. These latter proteins appear to interact with the cytoskeleton, promoting rearrangement and thus spore swelling, followed by release of nascent amoebae (Lydan \& Cotter, 1994, 1995; Lydan et al., 1994a, b). Nomarski-differential interference microscopy and transmission electron microscopy demonstrate that actin in dormant spores is present in large rod-shaped structures in both the nucleus and the cytoplasm; correlations are noted between the dephosphorylation of actin, disappearance of the actin rods, initiation of cytoplasmic streaming and spore swelling (Sameshima et al., 1994; Kishi et al., 1994, 1998). Mutants such as $s p l A^{-}$produce spores without phosphorylated actin and are only transiently dormant (Kishi et al., 1998).

The experiments described in this report show that the sori of fruiting bodies contain very high levels of ammonium phosphate that stimulate spore dormancy through the ACG osmosensor and its downstream effector PKA. This demonstrates that ammonia and ammonium ions interact with cAMP production in all stages of development. We suggest a model that explains most of the interactions between these two lowmolecular-mass morphogens.

\section{METHODS}

Reagents. L-Glutamine, $\gamma$-glutamyl monohydroxamate, Lmethionine sulphoximine (MSX) and Nessler's reagent were from Sigma. ADP was from Boehringer Mannheim. Media 
components were obtained from Oxoid. All other reagents were of the highest purity available.

Culture conditions. D. discoideum strains NC4 and V12 used in the study were parents of the respective prematurely maturing mutants SG1 and SG2; the null mutant $\mathrm{acg}^{-}$(Pitt et al., 1992) was employed in a few experiments. All strains were grown on three types of agar media: standard medium (SM) (Sussman, 1987), SM/2 (SM diluted 1:1 but with the agar concentration kept at $1.5 \%$ ), and glucose/salts agar, which requires that the food bacterium Escherichia coli $\mathrm{B} / \mathrm{r}$ (ATCC 12407) be prototrophic. The glucose/salts medium is believed to leave fewer unused nutrients in the agar and to result in sori with less moisture (Cotter et al., 1990). D. discoideum spores $\left(10^{4} \mathrm{ml}^{-1}\right)$ mixed with $E$. coli $\mathrm{B} / \mathrm{r}$ were spread on the three types of solid media and incubated at $22{ }^{\circ} \mathrm{C}$. The bacterial host was cleared by $72 \mathrm{~h}$ and fruiting bodies were initiated by $96 \mathrm{~h}$.

Germination conditions. Fruiting bodies were allowed to age for at least $2 \mathrm{~d}$ before spores were removed for germination experiments. Spores $2-4 \mathrm{~d}$ old were obtained by shaving the sori with the edge of glass slides, which were then dipped in $10 \mathrm{ml}$ water contained in a $50 \mathrm{ml}$ beaker. The suspended spores were vortexed in a glass test tube to break up clumps, and centrifuged for $5 \mathrm{~min}$ at $400 \mathrm{~g}$. The supernatant was used to determine ammonia and phosphate concentrations. The spores were resuspended in $10 \mathrm{mM}$ potassium phosphate buffer at $\mathrm{pH} 6.5$, washed twice by centrifugation in the phosphate buffer and resuspended in the buffer at a concentration of $1-7 \times 10^{7} \mathrm{ml}^{-1}$ for autoactivation experiments. In heat-induced activation experiments, spores were heat shocked at $45^{\circ} \mathrm{C}$ for $30 \mathrm{~min}$ and then the number was adjusted to $1-7 \times 10^{7} \mathrm{mi}^{-1}$. Spores germinated in volumes less than $5 \mathrm{ml}$ were kept in suspension in $10 \mathrm{ml}$ test tubes by slowly spinning micro-stir bars. Spore germination in volumes greater than $5 \mathrm{ml}$ utilized various sized flasks aerated on a temperaturecontrolled rotary shaker at 150 r.p.m. The progress of spore germination at room temperature was monitored by scoring at least 200 spores/amoebae every $60 \mathrm{~min}$ by phase-contrast microscopy as unswollen, swollen or emerged amoebae.

Sample preparation. During the germination experiments, samples were harvested by centrifugation at $400 \mathrm{~g}$ for $5 \mathrm{~min}$. The supernatants and pellets were separated and both were quickly frozen at $-20{ }^{\circ} \mathrm{C}$. The spore number in most pellets for enzyme analysis was $4 \times 10^{8}$; the spore number in pellets for RNA extraction was $1 \times 10^{8}$.

Protein extraction. Nitric-acid-washed glass beads $(300 \mu$, 212-300 $\mu \mathrm{m}$ diameter; Sigma) and $350 \mu \mathrm{l}$ extraction buffer [25 mM Tris/HCl (pH 7.8), $10 \mathrm{mM} \mathrm{L-glutamate,} 5 \mathrm{mM} \beta$ mercaptoethanol, $1 \mathrm{mM} \mathrm{MnCl}_{2}$ ] were added to spores or germinating spore pellets and the suspension was vortexed for $5 \times 20 \mathrm{~s}$ periods with intervening cooling on ice for $30 \mathrm{~s}$. Usually $60-70 \%$ of the cells were lysed by this procedure. The protein extract was decanted into a fresh tube, centrifuged at $100000 \mathrm{~g}$ for $10 \mathrm{~min}$ at $4{ }^{\circ} \mathrm{C}$ and stored on ice until use.

RNA extraction. Fresh cell pellets harvested from spores at various stages of germination were mixed with $300 \mu$ l diethylpyrocarbonate (DEPC) and nitric-acid-washed glass beads $(212-300 \mu \mathrm{m}$ diameter, Sigma) and $350 \mu \mathrm{l} 50 \mathrm{mM}$ Tris $/ \mathrm{HCl}$ (pH 8.4) containing 1\% DEPC and $2 \%$ SDS. The cells were disrupted as described above and the supernatant was mixed vigorously with an equal volume of phenol/chloroform (1:1). After centrifugation $(12000 \mathrm{~g}, 10 \mathrm{~min})$ the aqueous phase was collected and re-extracted twice more with phenol/ chloroform. Before the last extraction sodium acetate ( $\mathrm{pH} 4.7)$ was added to a final concentration of $0.4 \mathrm{M}$. The aqueous phase was then mixed with 2 vols $99 \%$ ethanol, and the RNA precipitated overnight and collected by centrifugation $\left(12000 \mathrm{~g}, 30 \mathrm{~min}, 4^{\circ} \mathrm{C}\right)$ was washed once in $75 \%$ ethanol and dried under vacuum. The final pellet was resuspended in sterile water and stored at $4{ }^{\circ} \mathrm{C}$ (Dunbar \& Wheldrake, 1997b).

Glutamine synthetase (GS) assay. GS activity was assayed by monitoring the formation of $\gamma$-glutamyl hydroxamate in the $\mathrm{Mn}^{2+}$-dependent transferase reaction as described by Dunbar \& Wheldrake (1995).

Northern analysis. The amount of GS mRNA formed during spore germination was determined by the procedures of Dunbar \& Wheldrake (1997b). To confirm that equal amounts of RNA were loaded in each lane, all RNA samples were diluted 1 in 500 and probed with a $3 \mathrm{~kb}$ EcoRI rRNA fragment labelled with $\left[\alpha-{ }^{32} \mathrm{P}\right] \mathrm{dCTP}$ by the random-primed method.

Ammonia analysis. At the $\mathrm{pH}$ values used in these experiments, the term ammonium should be used. However, the biologically active component is most likely to be ammonia (Davies et al., 1996) so the two terms will be used interchangeably. Samples $(1 \mathrm{ml})$ of spore washes and germination supernatants were mixed with $0.25 \mathrm{ml}$ Nessler's reagent (Sigma) and incubated at room temperature for $20 \mathrm{~min}$ before measuring $A_{480}$. Ammonia concentrations were determined by reference to a standard curve constructed with $\mathrm{NH}_{4} \mathrm{Cl}$. To confirm that the Nessler assay was specific, ammonia production was also measured by oxidation of $\mathrm{NADH}\left(A_{340}\right)$ at $30{ }^{\circ} \mathrm{C}$ as described by Pamula $\&$ Wheldrake $(1990)$ using pure bovine liver glucose dehydrogenase, and with an ammonia electrode.

In some experiments, ammonia in sori was determined by using a dry glass slide to harvest sori; the spores and matrix material were quickly transferred to a $10 \mu$ glass capillary tube. The contents of the capillary tube were rinsed into $10 \mathrm{ml}$ distilled, deionized water. The spores were removed by centrifugation and ammonia in the supernatant was determined with Nessler's reagent. The spores were resuspended in phosphate buffer and counted.

Phosphate analysis. Inorganic phosphate in spore washes and germination supernatants was determined by adding to each $1 \mathrm{ml}$ sample: $0.5 \mathrm{ml} 3 \% \mathrm{HClO}_{4}, 1.8 \mathrm{ml} 0.8 \% \mathrm{FeSO}_{4}$ (in $0.1 \mathrm{M}$ $\mathrm{H}_{2} \mathrm{SO}_{4}$ ) and $0.15 \mathrm{ml} 6.6 \%$ ammonium molybdate (in $3.5 \mathrm{M}$ $\mathrm{H}_{2} \mathrm{SO}_{4}$ ) and measuring $A_{620}$ after $20 \mathrm{~min}$ at room temperature. A standard curve was constructed with potassium phosphate (Fiske \& Subbarow, 1925).

Development on Millipore filters and agar surfaces. To produce fruiting bodies as free of extraneous nutrients as possible, cells were washed in $10 \mathrm{mM}$ potassium phosphate buffer and $5.5 \times 10^{8}$ cells per filter plated on cellulose nitrate membrane filters $(4.5 \mathrm{~cm}$ diameter, Millipore) resting on supporting filter pads saturated with $10 \mathrm{mM}$ potassium phosphate buffer. The plates were incubated at room temperature until fruiting bodies formed. In other experiments, $10 \mathrm{mM}$ MES buffer at $\mathrm{pH} 6.5$, free of phosphate, was used in place of $10 \mathrm{mM}$ potassium phosphate buffer.

Development of cells in micro-drops of less than $10 \mu$ l utilized $1.5 \%$ non-nutrient agar containing $10 \mathrm{mM}$ potassium phosphate or $10 \mathrm{mM}$ MES buffer. The cell number was adjusted to $10^{8} \mathrm{ml}^{-1}$ before the drops were plated on the agar surface with a micropipette (Cotter et al., 1990).

Reproducibility of experiments. Each experiment was done three or more times, with the mean and standard error of the mean (SEM) calculated where appropriate. Enzyme assays, 
ammonia determinations and phosphate determinations were done at least in triplicate for each experiment.

Much of the data are expressed in production or consumption by $10^{x}$ spores; this number is not entirely arbitrary since several inhibitory properties of spores are evident at this concentration.

\section{RESULTS}

\section{GS activity in spore extracts}

Crude extracts of dormant spores prepared by glassbead grinding $2 \mathrm{~d}$ after fruiting-body formation failed to reveal significant GS activity. To determine when and under what conditions GS returned to vegetative levels, spores of $D$. discoideum strain SG1 were washed in $10 \mathrm{mM}$ potassium phosphate buffer at $\mathrm{pH} 6.5$ and allowed to germinate by autoactivation (spontaneous germination). The germination process was highly reproducible in four separate experiments (Fig. 1). Similar germination kinetics were observed after spores were heat-activated and incubated in phosphate buffer (data not shown). Spore swelling began after $1 \mathrm{~h}$ incubation and the first amoebae were observed $2 \mathrm{~h}$ after the start of incubation. Germination was essentially complete by $5 \mathrm{~h}$. Autoactivation and heat-induced germination of the opposite mating type (strain SG2) gave similar results (data not shown).

The specific activity of GS in 2-4-d-old dormant spores was extremely low (Fig. 2) when compared to that in newly formed fruiting bodies (Dunbar \& Wheldrake,

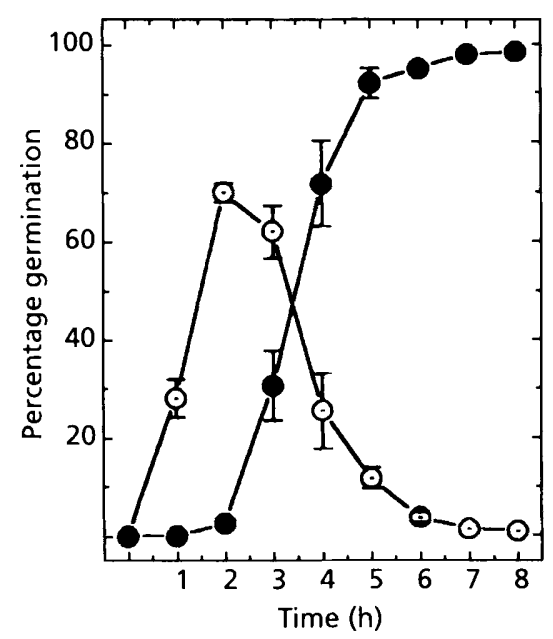

Fig. 1. Autoactivation of $\mathrm{SG} 1$ spores in $10 \mathrm{mM}$ potassium phosphate buffer at $\mathrm{pH}$ 6.5. Spores were incubated in $50-100 \mathrm{ml}$ volumes in $250 \mathrm{ml}$ flasks at $2-7 \times 10^{7} \mathrm{ml}^{-1}$. Each hour the percentage of the spore population that was swollen $(O)$ or present as nascent amoebae (0) was determined by phase-contrast microscopy; the mean \pm SEM for four separate experiments are plotted. Samples of spores/amoebae were pelleted by centrifugation, and the supernatant and pelleted cells were frozen separately.

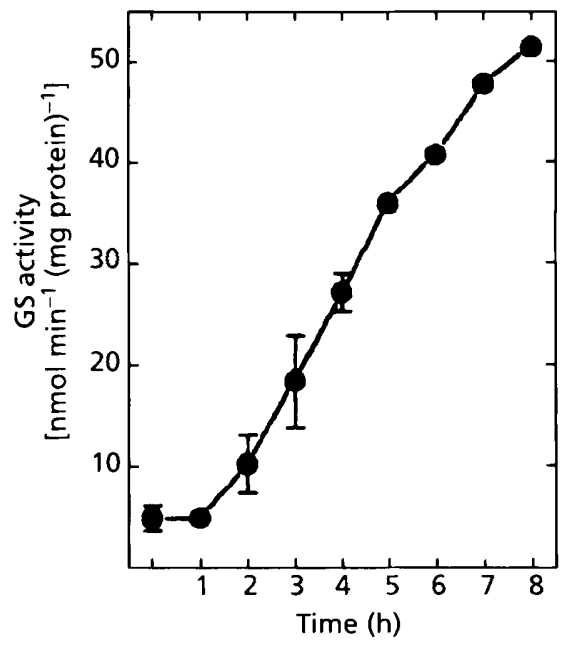

Fig. 2. GS activity in autoactivated SG1 spores. The mean \pm SEM are plotted for three separate experiments with 2-4-d-old spores.

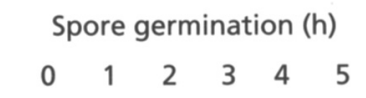

(a)

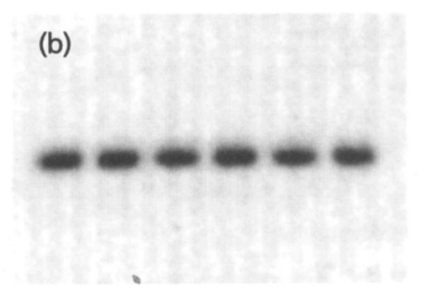

Fig. 3. Accumulation of GS mRNA during autoactivated SG1 germination. (a) RNA $(20 \mu \mathrm{g})$ isolated every hour throughout the $5 \mathrm{~h}$ of spore germination was electrophoresed, transferred to a nylon membrane and hybridized with a ${ }^{32} \mathrm{p}$-labelled $177 \mathrm{bp}$ PCR product of the GS gene. (b) RNA loading control; the same RNA samples as in (a) were electrophoresed on a separate gel and probed with an [ $\alpha$ - ${ }^{32}$ p]dCTP-labelled $3 \mathrm{~kb}$ ECORI rRNA probe.

1995). No increase was detectable during auto-activation until spores began to swell (Fig. 2). After $8 \mathrm{~h}$ incubation, activity had risen to near the vegetative- 


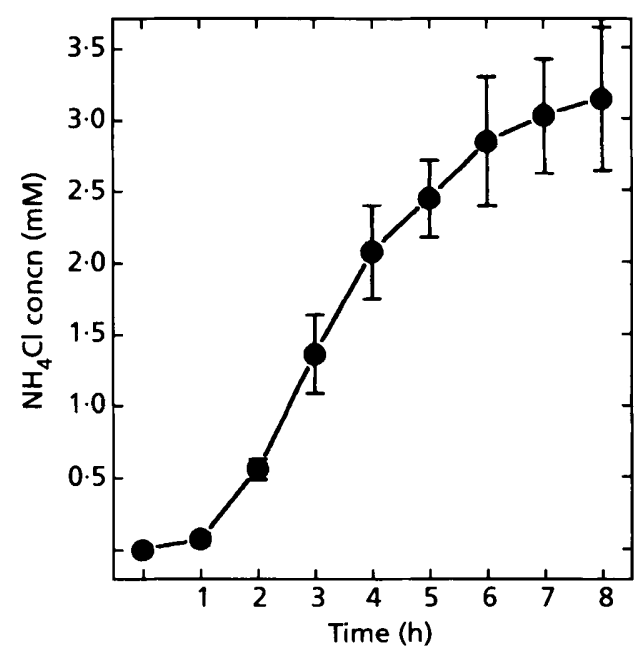

Fig. 4. Ammonia production during autoactivation of SG1 spores. The supernatants from four germination experiments were tested with Nessler's reagent. The spore numbers ranged from 2 to $7 \times 10^{7} \mathrm{ml}^{-1}$; however, the data are plotted as the amount of ammonia produced by a theoretical spore population of $10^{8} \mathrm{ml}^{-1}$. The means \pm SEM are shown.

growth level. The increase occurred in the absence of bacteria or axenic media, and thus growth was not required to induce the vegetative level of GS. The results were not strain dependent since spores of the opposite mating type (strain SG2) yielded nascent amoebae with the same specific activity as above (data not shown). Similar results were found for spores activated by heat shock (data not shown).

MSX at $5 \mathrm{mM}$ has been shown to completely inhibit GS activity in vitro (Dunbar \& Wheldrake, 1995, 1997c). The inhibitor did not delay autoactivation, but the nascent amoebae did not clump in suspension as readily as uninhibited cells (data not shown). Plating of nascent amoebae, from MSX-treated spores on agar surfaces in micro-drops, resulted in rapid aggregation similar to that seen with uninhibited nascent cells.

\section{Transcriptional control of GS}

Northern blotting indicated that the return of GS activity in nascent amoebae may be transcriptionally controlled (Fig. 3). Again, there were no significant differences between the transcription patterns of nascent amoebae generated by autoactivation or heat-induced germination of spores (data not shown).

\section{Ammonia production during spore germination}

Earlier studies using ${ }^{13} \mathrm{C}$ NMR suggested that the high concentrations of glutamine and trehalose, as well as of glutamate and asparagine, in dormant spores decreased during the $5 \mathrm{~h}$ of germination (Klein et al., 1990). The amino acids are probably used primarily as energy sources rather than for the synthesis of spore-germi-
Table 1. Ammonium concentration in supernatants from germinating spores

All values are normalized to $10^{8}$ spores $\mathrm{ml}^{-1}$ in phosphate buffer. Each entry represents the mean \pm SEM for three experiments.

\begin{tabular}{|lcc|}
\hline Strain & $\begin{array}{c}\text { Method of spore } \\
\text { activation }\end{array}$ & $\begin{array}{c}\text { Ammonium concn after } \\
\mathbf{5} \text { h germination }(\mathbf{m M})\end{array}$ \\
\hline SG1 & Autoactivated & $2 \cdot 47 \pm 0 \cdot 26$ \\
SG1 & Heat activated & $2 \cdot 17 \pm 0 \cdot 10$ \\
SG2 & Autoactivated & $2 \cdot 40 \pm 0 \cdot 33$ \\
SG2 & Heat activated & $2 \cdot 76 \pm 0 \cdot 50$ \\
\hline
\end{tabular}

nation proteins (Ennis, 1981; Klein et al., 1990; Cotter $e t$ al., 1992) and would probably be catabolized to carbon dioxide and ammonia.

When ammonia was measured in autoactivating SG1 spores as described in Methods, dilution of the supernatants was usually necessary because of the large quantity produced. The amount produced in $5 \mathrm{~h}$ depended directly upon spore concentration in the range $2-7 \times 10^{7} \mathrm{ml}^{-1}$. The data for four experiments were plotted as the concentration of ammonium produced by a normalized spore population of $10^{8} \mathrm{ml}^{-1}$ over $8 \mathrm{~h}$ (Fig. 4). Similar high levels of ammonia were released when SG1 spores were heat activated. Strain SG2 also released ammonia during germination (Table 1). Independent assays with a glutamate dehydrogenase coupled enzyme system (see Pamula \& Wheldrake, 1990) confirmed that the amine released by germinating spores was ammonia. There was a $98 \%$ agreement between the two methods (data not shown). Measurements with an ammonia electrode reconfirmed the above data.

\section{Ammonia-induced reversible inhibition of spore germination}

In several experiments, at very high spore densities, auto-induced spore germination was delayed and ammonia was detected in the time zero samples. This led us to examine (1) the effects of increasing concentrations of ammonia on spore germination, and (2) the concentration of ammonia in mature fruiting bodies. In initial experiments, the inhibitory effects of $5 \mathrm{mM}$ ammonium chloride and ammonium sulfate were primarily due to chloride and sulfate anions (data not shown). Since germinating spores produced ammonia in $10 \mathrm{mM}$ phosphate buffer in other experiments, phosphate was tested as a counterion. Low (14 mM) concentrations of ammonium in $10 \mathrm{mM}$ phosphate buffer, $\mathrm{pH} 7 \cdot 0$, had very little effect on spore germination (data not shown). At a moderate concentration $(28 \mathrm{mM})$ of ammonium, autoinduced spore germination proceeded rapidly after the short lag. Replacement of ammonium with potassium ions resulted in little or no lag (data not shown). The levels of GS in amoebae at $5 \mathrm{~h}$ were very similar in the 


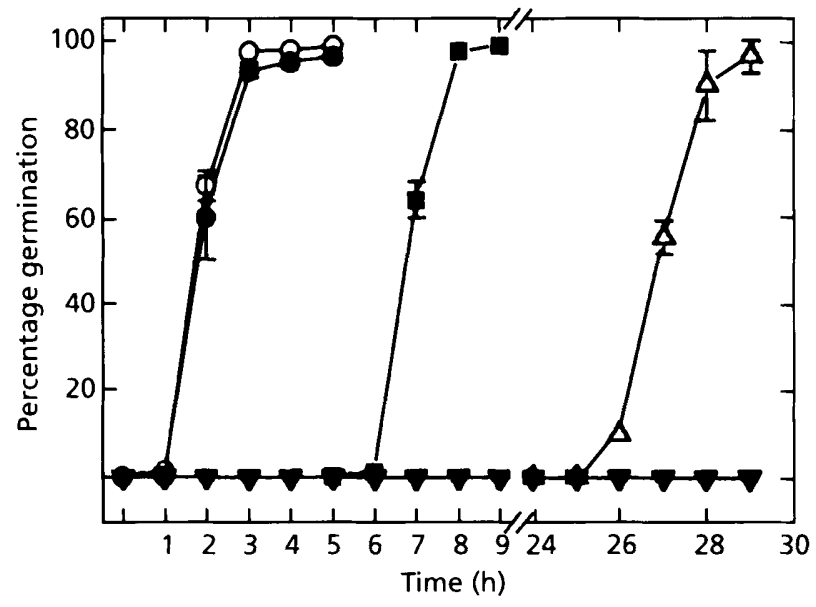

Fig. 5. Reversible inhibition of SG2 spore autoactivation by $69 \mathrm{mM}$ ammonium. Spores were harvested and washed three times with ammonium $(69 \mathrm{mM}) /$ phosphate $(50 \mathrm{mM})$ buffer at $\mathrm{pH} 7.0$. Samples in glass tubes were resuspended in the above buffer $(5 \mathrm{ml})(\boldsymbol{\nabla})$ with the aid of small stirring bars for $30 \mathrm{~h}$ at room temperature. At $0 \mathrm{~h}$, portions were centrifuged and resuspended in potassium $(14 \mathrm{mM}) /$ phosphate $(10 \mathrm{mM})$ buffer at $\mathrm{pH} 7.0(\mathrm{O})$, and in potassium $(69 \mathrm{mM}) /$ phosphate $(50 \mathrm{mM})$ buffer at $\mathrm{pH} 7.0(0)$. The spores resuspended in potassium solutions were incubated in glass tubes as above. At $5(\boldsymbol{D})$ and $24 \mathrm{~h}(\triangle)$ additional portions were centrifuged, resuspended in the potassium $(69 \mathrm{mM}) /$ phosphate $(50 \mathrm{mM})$ buffer at $\mathrm{pH} 7.0$, and incubated as above. The experiment was repeated three times and the means \pm SEM are plotted.

two cultures [control value, $38 \mathrm{nmol} \mathrm{m^{-1 }}$ (mg protein $)^{-1}$; ammonium value, $37 \mathrm{nmol} \mathrm{min}^{-1}$ (mg protein $\left.)^{-1}\right]$. Thus $28 \mathrm{mM}$ ammonium ion had no effect on the activity of GS in emerging amoebae.

Spores of strains SG1 and SG2 did not germinate in $100 \mathrm{mM}$ ammonium phosphate buffer at $\mathrm{pH} 6 \cdot 5-7 \cdot 0$ (data not shown). When spores of strain SG2 were harvested in an ammonium phosphate solution $(69 \mathrm{mM}$ ammonium and $50 \mathrm{mM}$ phosphate ion, $\mathrm{pH} 7 \cdot 0$ ), autoinduced spore germination was inhibited by $99 \%$ (Fig. $5)$. The few amoebae that emerged were normal in appearance and viable. Inhibition imposed by $69 \mathrm{mM}$ ammonium ion was relieved when spores were centrifuged and resuspended in phosphate buffer solutions containing either 14 or $69 \mathrm{mM}$ potassium ion (see Fig. 5). Relief was also observed when spores incubated for 5 , or even 24 , h with $69 \mathrm{mM}$ ammonium were pelleted and resuspended in $50 \mathrm{mM}$ phosphate containing $69 \mathrm{mM}$ potassium ion (see Fig. 5). These experiments were repeated three times and were remarkably reproducible.

In other experiments we extended the incubation of spores in $69 \mathrm{mM}$ ammonium for up to $7 \mathrm{~d}$ without loss in viability or ability to germinate upon removal of the inhibitory ion (data not shown). Similar germination kinetics are observed when spores are directly harvested from fruiting bodies and incubated in non-inhibitory phosphate buffers (Cotter \& Glaves, 1989).
Table 2. Ammonium concentrations in sori containing young dormant spores

All values are normalized to $10^{8}$ spores in $10 \mu \mathrm{l}$; each numerical entry represents the mean \pm SEM for three experiments.

\begin{tabular}{|llcc|}
\hline Strain & $\begin{array}{c}\text { Method of } \\
\text { harvesting }\end{array}$ & $\begin{array}{c}\text { Ammonium } \\
\text { concn }(\mathbf{m M})\end{array}$ & $\begin{array}{c}\text { Phosphate } \\
\text { concn }(\mathbf{m M})\end{array}$ \\
\hline SG1 & Wet slide & $124 \pm 24$ & $117 \pm 10$ \\
SGl & Dry capillary & $115 \pm 15$ & $132 \pm 31$ \\
SG2 & Wet slide & $227 \pm 27$ & $116 \pm 10$ \\
SG2 & Dry capillary & $223 \pm 30$ & $178 \pm 30$ \\
NC4 & Dry capillary & $275 \pm 32$ & $123 \pm 15$ \\
V12 & Dry capillary & $246 \pm 28$ & $238 \pm 20$ \\
\hline
\end{tabular}

\section{Ammonium and phosphate levels in sori of $D$. discoideum}

The above experiments led us to examine ammonium levels in young fruiting bodies. The concentrations of ammonium and phosphate were surprisingly high (over $100 \mathrm{mM}$ ) whether the matrix and spores were harvested by a wet slide as in the experiments described above, or a dry slide with transfer to a capillary tube, followed by dispersion in distilled water (Table 2). The results in Table 2 are normalized to $10^{8}$ spores per $10 \mu$ sori but approximately $5 \times 10^{7}$ spores were usually harvested from relatively dry fruiting bodies into a $10 \mu \mathrm{l}$ capillary tube and hence the concentrations of ammonium and phosphate would be half of those recorded in Table 2; nevertheless these ammonium concentrations exceeded the $69 \mathrm{mM}$ sufficient to block spore germination (see Fig. 5). When the spore number was closer to $10^{8}$, loading of capillaries was very difficult. Even $5 \times 10^{7}$ spores occupy a substantial portion of the $10 \mu$ l volume shared with the soluble matrix components and the stalk tissue. Thus, the values in Table 2 may be minimal estimates that rise rapidly when fruiting bodies dried slightly. The volume of the sorus is proportional to the cube of the radius, so a decrease in radius by half during ageing/drying would increase the ammonium concentration eightfold, keeping the spores dormant.

The initial concentration of ammonium and phosphate in sori of young fruiting bodies was independent of the type of growth medium, but as fruiting bodies aged, the sori on SM agar had a tendency to swell with a concomitant decrease in ammonium and phosphate concentration (data not shown). This may account for the observation that spores of strains SG1 and SG2 are unstable in fruiting bodies produced on SM agar and may germinate in the sori (Cotter et al., 1990). The stalk tissue of a fruiting body does not appear to act as a straw transferring ammonium and phosphate from the spent growth medium into the sorus. Rather, the compounds are produced endogenously, for when cells were washed in MES buffer and allowed to fruit on filters containing MES buffer, the resulting sori contained levels of ammonium and phosphate similar to those of Table 2 (data not shown). 


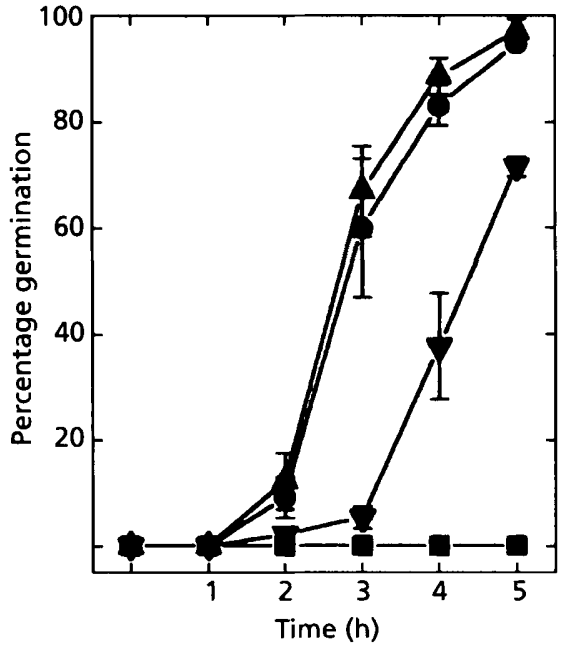

Fig. 6. Germination inhibition of SG2 autoactivation by ammonia. Spores were washed three times by centrifugation with $10 \mathrm{mM}$ potassium phosphate buffer at $\mathrm{pH} 6.5$. The pellets were resuspended at a density of $2-5 \times 10^{7}$ spores $\mathrm{ml}^{-1}$ in one of four solutions: $50 \mathrm{mM}$ potassium phosphate buffer at $\mathrm{pH} 6.2$ (A), $50 \mathrm{mM}$ ammonium phosphate buffer at pH $6.2(\nabla), 50 \mathrm{mM}$ potassium phosphate buffer at $\mathrm{pH} 7.2$ (O), and $50 \mathrm{mM}$ ammonium phosphate buffer at pH $7.2(\mathbb{0})$. All of the solutions were brought to the appropriate $\mathrm{pH}$ using $\mathrm{KOH}$. The means \pm SEM are plotted for three separate experiments.

\section{The effects of $\mathrm{pH}$ on the ratio of ammonia/ammonium and the dormancy of spores}

Ammonia affects other parts of the developmental life cycle including aggregation density, period of slug migration and culmination. Davies et al. (1993) suggested that the active species is the unprotonated form, ammonia, as a result of its greater membrane mobility. Whether ammonia exerts a greater effect than ammonium ions in blocking spore germination was tested by incubating spores of strain SG 2 in $50 \mathrm{mM}$ ammonium phosphate buffer brought to $\mathrm{pH} 6 \cdot 2$ and $7 \cdot 2$ with $\mathrm{KOH}$ (Fig. 6). At pH 7.2 the spores were fully inhibited whereas at $\mathrm{pH} 6.2$ spores germinated but with a long lag. In osmotic controls using $50 \mathrm{mM}$ potassium phosphate brought to $\mathrm{pH} 6.2$ and 7.2 using $\mathrm{KOH}$, germination began after a lag of only $1 \mathrm{~h}$. The HendersonHasselbach equation predicts that the concentration of ammonia decreases by $90 \%$ as the $\mathrm{pH}$ decreases from $7 \cdot 2$ to $6 \cdot 2$, whereas the ammonium ion concentration increases by only $0.8 \%$. Clearly, it is ammonia in the ammonia/ammonium pair that blocks germination when potassium phosphate does not stimulate the osmosensor ACG to maintain spore dormancy.

\section{Spores of the $\mathrm{acg}^{-}$null mutant are not inhibited by ammonia}

The availability of an $\mathrm{acg}^{-}$mutant allowed us to test one possible target of ammonia action. This mutant produces normal-looking fruiting bodies (Pitt et al., 1992) in which spores remain dormant through the activity of
Table 3. Autoactivation of strains SG1 and $\mathrm{acg}^{-}$in $50 \mathrm{mM}$ ammonium or potassium phosphate buffers

Spores were incubated in the buffers at $10^{7} \mathrm{ml}^{-1}$ for $12 \mathrm{~h}$.

\begin{tabular}{|lccc|}
\hline Strain & $\begin{array}{c}\text { Ammonium } \\
\text { phosphate }^{*}\end{array}$ & $\begin{array}{c}\text { Potassium } \\
\text { phosphate }\end{array}$ & $\begin{array}{c}\text { Percentage } \\
\text { germination } \dagger\end{array}$ \\
\hline SG1 & + & - & $2 \cdot 0 \pm 1 \cdot 3$ \\
SG1 & - & + & $97 \cdot 1 \pm 3 \cdot 2$ \\
acg $^{-}$ & + & - & $85 \cdot 3 \pm 6 \cdot 0$ \\
acg $^{-}$ & - & + & $92 \cdot 4 \pm 5 \cdot 2$ \\
\hline
\end{tabular}

*50 mM ammonium or potassium dihydrogen phosphate was titrated to $\mathrm{pH} 7 \cdot 2$ with $\mathrm{KOH}$.

tShown as mean germination \pm SEM of three experiments after $12 \mathrm{~h}$ incubation

discadenine (van Es et al., 1996). However, such spores lack the dormancy response to high osmotic pressure that can be generated by sucrose concentrations near $250 \mathrm{mM}$ (van Es et al., 1996). Washed spores of $\mathrm{acg}^{-}$ were not inhibited from germinating in $50 \mathrm{mM}$ ammonium phosphate solutions titrated to $\mathrm{pH} 7 \cdot 2$, while spores of strain SG1 were inhibited (Table 3). Both strain SG1 and $\mathrm{acg}^{-}$spores germinated in the osmotic control solutions containing potassium phosphate buffer at $\mathrm{pH}$ 7.2. In other experiments, $\mathrm{acg}^{-}$spores germinated in $100 \mathrm{mM}$ ammonium phosphate solutions at $\mathrm{pH} 7 \cdot 2$ (data not shown).

\section{DISCUSSION}

Ammonia and ammonium ions are lethal to both vertebrates and invertebrates at concentrations between 0.5 and $5 \mathrm{mM}$ (see Withers, 1992). Thus, the social amoebae may be unique in using very high concentrations of ammonia as a morphogen controlling development. However, the reaction of social amoebae is usually avoidance. The organism either moves away from the source of the ammonia, or attempts to consume the morphogen.

GS activity is very high in sporulating cells of $D$. discoideum, allowing regulation of ammonia concentrations during culmination (Dunbar \& Wheldrake, 1995, 1997a). However GS activity was virtually absent in dormant spores $2-4 \mathrm{~d}$ after culmination, suggesting that ammonia cannot be assimilated and instead accumulates in the sori of mature fruiting bodies. The GS activity began to rise $1 \mathrm{~h}$ after spores were induced to germinate by autoactivation or heat-induction. It continued to increase even after $5 \mathrm{~h}$ when spore germination was complete: the full vegetative level was not attained until $8 \mathrm{~h}$. Since spore germination uses endogenous reserves and bacteria were not present in the culture, cell growth is not required to return the enzyme to vegetative levels. The transcriptional control of GS activity shown by mRNA blotting is similar to that found during culmination (Dunbar \& Wheldrake, 1997b). At the 


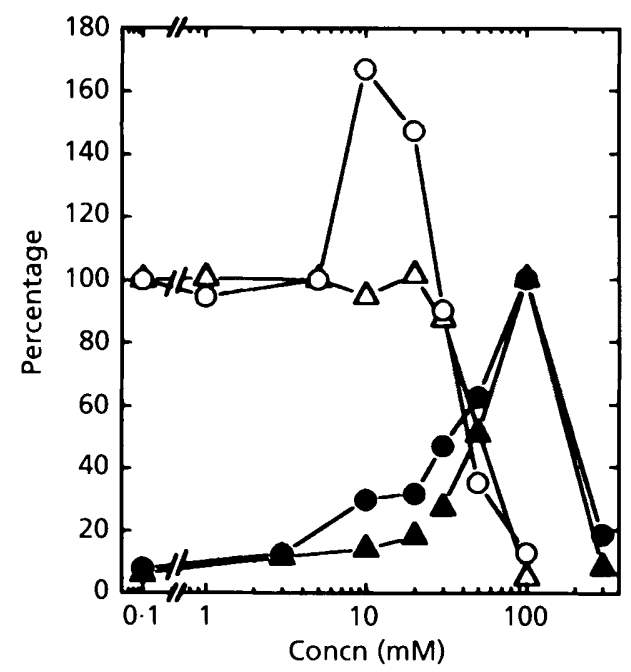

Fig. 7. Modulation of ACA and ectopically expressed ACG activities by sodium chloride and ammonium chloride. The data are replotted from Figs 1c and 3b of Schaap et al. (1995). ACA relay activities were examined by incubating aggregationcompetent cells at $10^{8} \mathrm{ml}^{-1}$ in 20 mM HEPES buffer at $\mathrm{pH} 7.4$ for $15 \mathrm{~min}$ with various concentrations of sodium chloride $(\triangle)$ and ammonium chloride $(O)$. The cells were then stimulated with 2'HCAMP in $50 \mathrm{mM}$ DTT for $5 \mathrm{~min}$; the reaction was terminated by addition of $3.5 \%$ perchloric acid. A similar protocol was used to measure in vivo CAMP accumulation by aca-/ACG cells under the influence of sodium chloride $(\boldsymbol{\Delta})$ and ammonium chloride (0) for $15 \mathrm{~min}$, except that cells were starved for 1-2 h and only $50 \mathrm{mM}$ DTT was added at the time of harvest. Cell lysates in both assays were neutralized with potassium bicarbonate and CAMP was measured by isotope dilution (see Schaap et al., 1995 for additional details).

same time that GS activity is increasing in germinating spores, ammonia is being released in what appears to be a futile ammonia cycle. Previous work suggests that a substantial amount of ammonia released during germination is derived from the degradation of endogenous glutamine, glutamate, asparagine and other amino acids (Ennis, 1981; Jackson et al., 1982; Klein et al., 1990). Since exogenous ammonium at $28 \mathrm{mM}$ did not modulate GS activity, the enzyme appears to be an integral part of the germination programme; i.e. it is not regulated by the environment, but is synthesized once the commitment to germination occurs. There is evidence that GS has a major function other than the synthesis of glutamine; i.e. it may be required to regulate free ammonia in various compartments of cells (Cotter $e t$ al., 1992; Dunbar \& Wheldrake, 1995, 1997a). Thus the enzyme may return as part of the preparation for normal vegetative growth, but it also may modulate the level of ammonia in the germination buffer.

The effects of various concentrations of ammonia during aggregation, slug migration and culmination were confusing until the work of Schaap et al. (1995), who studied the activity of ACA (adenylyl cyclase for aggregation) and ACG (expressed ectopically) in vegetative cells exposed to various osmotic agents. A portion of their data is replotted in Fig. 7 to aid the following discussion. At $100-250 \mathrm{mM}$, substances such as sucrose, glucose and polyalcohols effectively maintain spore dormancy (Cotter, 1977) by stimulating ACG to its maximum activity (van Es et al., 1996; Virdy et al., 1999). At concentrations near $100 \mathrm{mM}$, any exogenous, non-penetrating substance such as potassium phosphate, sodium chloride, ammonium chloride or ammonium phosphate can activate ACG through its osmosensing function (see Fig. 7). At concentrations of $300 \mathrm{mM}$ or more, ACG is inhibited and heat-activated spores are unable to return to dormancy because of partial dehydration (Cotter, 1977). At lower concentrations such as between 50 and $69 \mathrm{mM}$, ammonium phosphate (depending upon the $\mathrm{pH}$ ) inhibits spores from germinating in a fully reversible manner whereas potassium phosphate does not. This suggests that ammonium phosphate is not acting via the osmosensing function of ACG. Ammonium chloride is a more effective activator of ACG than sodium chloride at concentrations around $10-50 \mathrm{mM}$ (see Fig. 7). The $\mathrm{pH}$ of the cytosol of amoebae is normally 7:2-7.4 (Satre et al., 1989), and it can be decreased to 6.4 with weak acids such as propionic acid (Satre et al., 1989), or alternatively raised to 7.9 with weak bases (Van Lookeren Campagne et al., 1989). The activity of ACG is highly $\mathrm{pH}$ dependent and peaks around $\mathrm{pH} 7 \cdot 8$ with little activity below $\mathrm{pH} 7 \cdot 0$ (Schaap et al., 1995). We suggest that prevention of spore germination and enhanced activation of ACG by ammonium salts over potassium or sodium salts at $50-69 \mathrm{mM}$ is a result of slight alkalinization of the spores since the active species of the ammonia/ ammonium ion pair is ammonia. Any increase in $\mathrm{pH}$ in the cortical layers of the spore would stimulate the plasma-membrane-bound ACG without greatly changing the overall cytosolic $\mathrm{pH}$. Thus, both high $(100 \mathrm{mM})$ and moderate $(50-69 \mathrm{mM})$ concentrations of ammonium phosphate may maintain spore dormancy in sori by activating ACG through an osmotic as well as a $\mathrm{pH}$ effect. The evidence that $\mathrm{acg}^{-}$spores are not inhibited by either $250 \mathrm{mM}$ sucrose (van Es et al., 1996) or $50 \mathrm{mM}$ ammonium phosphate at $\mathrm{pH} 7 \cdot 2$ (Table 3 ) is consistent with the above hypothesis.

Concentrations of ammonium phosphate below $50 \mathrm{mM}$ in sori, resulting from dew formation at high relative humidities, do not maintain spore dormancy without the aid of other autoinhibitors such as discadenine (Abe et al., 1976). When unwashed dormant spores are diluted to $10^{8} \mathrm{ml}^{-1}$, they often do not germinate spontaneously in phosphate buffer (unpublished), nor in response to nutrient media (Abe et al., 1976; Zinda \& Singleton, 1998). Since the concentration of ammonium phosphate is then only $1-3 \mathrm{mM}$, dormancy must be maintained by other factors such as discadenine (Abe et al., 1976; Gauthier et al., 1997). Discadenine may function through activating the histidine kinase DHKB, which then inhibits RegA hydrolysis of cAMP produced by ACG (Zinda \& Singleton, 1998). At low relative humidities when fruiting bodies are relatively dry, wildtype spores would be subjected to high concentrations of ammonium phosphate and discadenine, both conditions favouring the maximum production of CAMP by ACG 
Ammonium phosphate promotes spore dormancy

and its minimal hydrolysis by the phosphodiesterase activity of RegA. The regulation of spore dormancy through maximal stimulation of cAMP and therefore maximum stimulation of PKA may be one of several times in the life cycle that development must be driven by at least two independent signals precisely controlled both spatially and temporally (Thomason et al., 1998). That precise control of PKA activity is at the centre of regulation is indicated by studies with null mutants of ACA expressing just $1 \cdot 6$ times the catalytic subunit activity of PKA in wild-type cells (Wang \& Kuspa, 1997). Such mutants rapidly form complete fruiting bodies with viable spores. It may be significant that an optimal concentration of ammonium $(10-20 \mathrm{mM})$ increases ACA activity up to 1.7 times that given by the same concentration of sodium. At $50 \mathrm{mM}$ and above, however, both sodium chloride and ammonium chloride are highly inhibitory to ACA activity (Fig. 7; Schaap et al., 1995). The very large shift in ACA activity from stimulation to inhibition over a narrow range of ammonia concentrations may account for the confusion in the literature on the effects of ammonia upon cAMP accumulation (Riley \& Barclay, 1990; Williams et al., 1984).

The work reported here in conjunction with that of others suggests that the functions of ACA, GS and ACG are coupled in a sequential way during development. As much as $70 \mathrm{mM}$ exogenously added ammonium chloride is required to block culmination (Davies et al., 1993), which is probably triggered by a decrease in the ammonia concentration of the slug as originally suggested by Schindler \& Sussman $(1977,1979)$ and shown by Wilson \& Rutherford (1978). The decrease in ammonia to $10-20 \mathrm{mM}$ by an increase in GS activity (Dunbar \& Wheldrake, 1995, 1997a, b, c,) would stimulate ACA to produce CAMP, in turn activating PKA almost twofold in the prespore region of the slug, and resulting in culmination. A marked rise in cAMP has been noted around the time of culmination (Abe \& Yanagisawa, 1983). After fruiting-body formation is nearly complete, a decrease in GS activity in sporulating cells (Dunbar \& Wheldrake, 1995, 1977a) without a corresponding decrease in ammonia production in dying stalk cells, would result in ammonia accumulation and severe inhibition of ACA activity (see Fig. 7). This could potentially decrease cAMP production and PKA activity, triggering spore germination (van Es et al., 1996; Virdy et al., 1999). However, it is at this time in development that acg is transcribed and translated in spores (Pitt et al., 1992). Replacing ACA with ACG allows increasing concentrations of ammonia to act as osmotic and $\mathrm{pH}$ modifying agents stimulating ACG to produce cAMP, and thus promoting high PKA activity to maintain spore dormancy. Various histidine kinases may regulate RegA to fine tune the level of cAMP, both during culmination and post-sporulation (Shaulsky et al., 1998; Thomason et al., 1998; Zinda \& Singleton, 1998). The above model may work in conjunction with a decrease in the acidification of vesicles by ammonia (Davies et al., 1996) since lysosomal cysteine proteinases remain in a non- acidified, unactivated state in dormant spores (North et al., 1990, 1996; Cotter et al., 1997).

\section{NOTE ADDED IN PROOF}

Recently, a third adenylyl cyclase activity (ACB), inhibited by high osmolarity, has been discovered by Meima $\&$ Schaap (1999). The enzyme may play a role similar to that postulated for ACA in the initiation and completion of culmination.

\section{ACKNOWLEDGEMENTS}

The authors are grateful for the technical support of Mr Keith Gale, Mr Dave Cervi and Mr John Marshall. This work was supported by grants from NSERC-Canada and a travel grant from Flinders University to D. A. Cotter.

\section{REFERENCES}

Abe, K. \& Yanagisawa, Y. (1983). A new class of rapidly developing mutants in Dictyostelium discoideum: implications for cyclic AMP metabolism and cell differentiation. Dev Biol 95 , 200-210.

Abe, H., Uchiyama, M., Tanaka, Y. \& Saito, H. (1976). Structure of discadenine, a spore germination inhibitor from the cellular slime mold Dictyostelium discoideum. Tetrahedron Lett 42, 3807-3810.

Bonner, J. T. (1993). Proteolysis and orientation in Dictyostelium slugs. J Gen Microbiol 139, 2319-2322.

Cotter, D. A. (1977). The effects of osmotic pressure changes on the germination of Dictyostelium discoideum spores. Can J Microbiol 23, 1170-1177.

Cotter, D. A. \& Glaves, M. L. (1989). Temporal control of autoactivator synthesis and secretion during spontaneous spore germination in Dictyostelium discoideum. Arch Microbiol 152, 44-51.

Cotter, D. A., Satre, M. \& Klein, G. (1990). Germination of Dictyostelium discoideum spores: inhibition of the autoactivation pathway by vanadate. J Gen Microbiol 136, 841-845.

Cotter, D. A., Sands, T. W., Virdy, K. J., North, M. J., Klein, G. \& Satre, M. (1992). Patterning of development in Dictyostelium discoideum: factors regulating growth, differentiation, spore dormancy and germination. Biochem Cell Biol 70, 892-919.

Cotter, D. A., Cavallo, D., Gale, K. E., Sands, T. W. \& North, M. J. (1997). Roles of proteinases in development of Dictyostelium. In Dictyostelium: A Model System for Cell and Developmental Biology, pp. 325-335. Edited by Y. Maeda, K. Inouye \& I. Takeuchi. Tokyo: Universal Academic Press.

Dahlberg, K. R. \& Cotter, D. A. (1978). Autoactivation of spore germination in mutant and wild type strains of Dictyostelium discoideum. Microbios 23, 153-166.

Davies, L., Satre, M., Martin, J. B. \& Gross, J. D. (1993). The target of ammonia action in Dictyostelium. Cell 75, 321-327.

Davies, L., Farrar, N. A., Satre, M., Dottin, R. P. \& Gross, J. D. (1996). Vacuolar $\mathrm{H}^{+}$-ATPase and weak base action in Dictyostelium. Mol Microbiol 22, 119-126.

Dunbar, A. J. \& Wheldrake, J. F. (1995). Evidence for a developmentally regulated prespore-specific glutamine synthetase in the cellular slime mould Dictyostelium discoideum. Microbiology $141,1125-1130$. 
Dunbar, A. J. \& Wheldrake, J. F. (1997a). Ammonia metabolism during the development of Dictyostelium discoideum and the role of glutamine synthetase. In Dictyostelium: A Model System for Cell and Developmental Biology, pp. 337-348. Edited by Y. Maeda, K. Inouye \& I. Takeuchi. Tokyo: Universal Academic Press.

Dunbar, A. J. \& Wheldrake, J. F. (1997b). Analysis of mRNA levels for developmentally regulated prespore specific glutamine synthetase in Dictyostelium discoideum. Dev' Growth Differ 39, 617-624.

Dunbar, A. J. \& Wheldrake, J. F. (1997c). Effect of the glutamine synthetase inhibitor, methionine sulfoximine, on the growth and differentiation of Dictyostelium discoideum. FEMS Microbiol l.ett 151, 163-168.

Ennis, H. L. (1981). Changes in free anino acid levels during cellular slime mold spore and microcyst germination. Arch Biochem Bioplys 209, 371-375.

van Es, S., Virdy, K. J., Pitt, G. S., Meima, M., Sands, T. W., Devreotes, P. N., Cotter, D. A. \& Schaap, P. (1996). Adenylyl cyclase G, an osmosensor controlling germination of Dictyostelium spores. J Biol Chem 271, 23623-23625.

Fiske, C. H. \& Subbarow, Y. (1925). The colorimetric determination of phosphorus. J Biol Chem 66, 375-400.

Gauthier, M. L., Lydan, M. A., O'Day, D. H. \& Cotter, D. A. (1997). Endogenous autoinhibitors regulate changes in actin tyrosine phosphorylation during Dictyostelium spore germination. Cell Signalling 9, 79-83.

Glaves, M. L. \& Cotter, D. A. (1989). Environmental parameters limiting spore germination in a spontaneously germinating mutant of Dictyostelium discoideum. Mycologia 81, 115-121.

Ihara, M., Tanaka, Y., Hashimoto, Y. \& Yanagisawa, K. (1990). Partial purification and some properties of spore germination promoter(s) for Dictyostelium discoideum excreted by Klebsiella aerogenes. Agric Biol Chem 54, 2619-2627.

Jackson, D. P., Chan, A. H. \& Cotter, D. A. (1982). Utilization of trehalose during Dictyostelium discoideum spore germination. Det'Biol 90, 369-374.

Kishi, Y., Chijiiwa, Y., Sameshima, M. \& Hashimoto, Y. (1994). Differential interference microscopy of intranuclear rods in Dictyostelium discoideum spores. Cytologia 59, 453-460.

Kishi, Y., Clements, C., Mahadeo, D. C., Cotter, D. A. \& Sameshima, M. (1998). High levels of actin tyrosine phosphorylation : correlation with the dormant state of Dictyostelium spores. J Cell Sci 111, 2923-2932.

Klein, G., Cotter, D. A., Martin, J. B. \& Satre, M. (1990). A naturalabundance ${ }^{13} \mathrm{C}$-NMR study of Dictyostelium discoideum metabolism: monitoring of the spore germination process. Eur $J$ Bioclom 193, 135-142.

Krivanek, J. O. \& Krivanek, R. C. (1965). Evidence for transaminase activity in the slime mold Dictyostelium discoideum Raper. Biol Bull 129, 295-302.

Lydan, M. A. \& Cotter, D. A. (1994). Spore swelling in Dictyostelium is a dynamic process mediated by calmodulin. FEMS Microbiol Lett 115, 137-142.

Lydan, M. A. \& Cotter, D. A. (1995). The role of $\mathrm{Ca}^{2+}$ during spore germination in Dictyostelium: autoactivation is mediated by the mobilization of $\mathrm{Ca}^{2+}$ while amoebal emergence requires entry of external $\mathrm{Ca}^{2+}$. J Cell Sci 108, 1921-1930.

Lydan, M. A., Cotter, D. A. \& O’Day, D. H. (1994a). Stage-specific changes in protein phosphorylation during spore germination in
Dictyostelium: role of calmodulin. Biochem Biophys Res Commun 201, 430-435.

Lydan, M. A., Cotter, D. A. \& O'Day, D. H. (1994b). Calmodulin function and calmodulin- binding proteins during autoactivation and spore germination in Dictyostelium discoideum. Cell Signal 6, 751-762.

Loomis, W. F. (1975). Dictyostelium discoideum: a Developmental System. New York: Academic Press.

Meima, M. E. \& Schaap, P. (1999). Fingerprinting of adenylyl cyclase activities during Dictyostelium development indicates a dominant role for adenylyl cyclase $B$ in terminal differentiation. Dev Biol 212, in press.

North, M. J. \& Cotter, D. A. (1991). Regulation of cysteine proteinases during different pathways of differentiation in cellular slime molds. Dev Genet 12, 154-162.

North, M. J., Cotter, D. A. \& Franek, K. J. (1990). Dictyostelium discoideum spore germination: increases in proteinase activity are not directly coupled to the emergence of myxamoebae. J Gen Microbiol 136, 835-840.

North, M. J., Nicol, K., Sands, T. W. \& Cotter, D. A. (1996). Acidactivatable cysteine proteinases in the cellular slime mold Dictyostelium discoideum. J Biol Chem 271, 14462-14467.

Oyama, M. \& Blumberg, D. D. (1986). Cyclic AMP and $\mathrm{NH}_{3} / \mathrm{NH}_{4}^{+}$ both regulate cell-type-specific mRNA accumulation in the cellular slime mold Dictyostelium discoideum. Dev Biol 117, 557-566.

Pamula, F. \& Wheldrake, J. F. (1990). Activation of the NADH dependent glutamate dehydrogenase during morphogenesis in Dictyostelium discoideum. Biochem Int 20, 623-632.

Pamula, F. \& Wheldrake, J. F. (1991). The NAD-dependent glutamate dehydrogenase from Dictyostelium discoideum: purification and properties. Arch Biochem Biophys 291, 225-230.

Pamula, F. \& Wheldrake, J. F. (1992). The effect of AMP on the NAD-dependent glutamate dehydrogenase during activation and morphogenesis in the cellular slime moulds. J Gen Microbiol 138, 1935-1940.

Pamula, F. \& Wheldrake, J. F. (1996). Kinetic properties and the mechanism of activation of NAD-dependent glutamate dehydrogenase from Dictyostelium discoideum. Biochem Mol Biol lnt 38, 729-738.

Pitt, G. S., Milona, N., Borleis, J., Lin, K. C., Reed, R. R. \& Devreotes, P. N. (1992). Structurally distinct and stage specific adenylyl cyclase genes play different roles in Dictyostelium development. Cell 69, 305-315.

Raper, K. B. (1984). The Dictyostelids. Princeton, NJ: Princeton University Press.

Riley, B. B. \& Barclay, S. L. (1990). Ammonia promotes accumulation of intracellular cAMP in differentiating amoebae of Dictyostelium discoideum. Development 109, 715-722.

Sameshima, M., Chijiiwa, Y., Kishi, Y. \& Hashimoto, Y. (1994). Novel actin rods appeared in spores of Dictyostelium discoideum. Cell Struct Funct 19, 189-194.

Satre, M., Martin, J. B. \& Klein, G. (1989). Methyl phosphonate as a ${ }^{31} \mathrm{P}$ NMR probe for intracellular $\mathrm{pH}$ measurements in $D$. discoideum. Biochimie 71, 941-948.

Schaap, P, Brandt, R. \& van Es. (1995). Regulation of Dictyostelium adenylyl cyclases by morphogen-induced modulation of cytosolic $\mathrm{pH}$ or $\mathrm{Ca}^{2+}$ levels. Dev Biol 168, 179-188.

Schindler, J. \& Sussman, M. (1977). Effect of $\mathrm{NH}_{3}$ on c-AMP associated activities and extracellular c-AMP production in 
Dictyostelium discoideum. Biochem Biophys Res Commun 79, 611- 617 .

Schindler, J. \& Sussman, M. (1979). Inhibition by ammonia of intracellular cAMP accumulation in Dictyostelium discoideum: its significance for the regulation of morphogenesis. Dev Genet 1 , 13-20.

Shaulsky, G., Fuller, D. \& Loomis, W. F. (1988). A cAMP phosphodiesterase controls PKA- dependent differentiation. Development 125, 691-699.

Sussman, M. (1987). Cultivation and synchronous morphogenesis of Dictyostelium under controlled experimental conditions. Methods Cell Biol 28, 9-29.

Thomason, P. A., Traynor, D., Cavet, G., Chang, W.-T., Harwood, A. J. \& Kay, R. R. (1998). An intersection of the CAMP/PKA and two component signal transduction systems in Dictyostelium. EMBO J 17, 2838-2845.

Van Lookeren Campagne, M. M., Aerts, R. J., Spek, W., Firtel, R. A. \& Schaap, P. (1989). Cyclic-AMP-induced elevation of intracellular $\mathrm{pH}$ precedes, but does not mediate, the induction of prespore differentiation in Dictyostelium discoideum. Development 105, 401-406

Virdy, K. J., Sands, T. W., Kopko, S. H., van Es, S., Meima, M.,
Schaap, P. \& Cotter, D. A. (1999). High cAMP in spores of Dictyostelium discoideum : association with spore dormancy and inhibition of germination. Microbiology 145, 1883-1890.

Wang, B. \& Kuspa, A. (1997). Dictyostelium development in the absence of cAMP. Science 277, 251-254.

Williams, G. B., Elder, E. M. \& Sussman, M. (1984). Modulation of the cAMP relay in Dictyostelium discoideum by ammonia and other metabolites: possible morphogenetic consequences. Dev Biol 105, 377-388.

Wilson, J. B. \& Rutherford, C. L. (1978). ATP, trehalose, glucose, and ammonium ion localization in the two cell types of Dictyostelium discoideum. J Cell Physiol 94, 37-46.

Withers, P. C. (1992). Comparative Animal Physiology. Orlando, FL: Harcourt Brace Jovanovich.

Wright, B. E. \& Bard, S. (1963). Glutamate oxidation in the differentiating slime mold. I. Studies in vivo. Biochim Biophys Acta 71, 45-49.

Zinda, M. J. \& Singleton, C. K. (1998). The hybrid histidine kinase $d h k B$ regulates spore germination in Dictyostelium discoideum. Dev Biol 196, 171-183.

Received 22 July 1998; revised 8 April 1999; accepted 20 April 1999. 